\title{
COMPOSIÇÃO FÍSICO-QUÍMICA DE UVAS PARA VINHO FINO EM CICLOS DE VERÃO E INVERNO ${ }^{1}$
}

\author{
RENATA VIEIRA DA MOTA ${ }^{2}$, CAMILA PINHEIRO CARVALHO SILVA ${ }^{3}$, \\ ANA CAROLINA FAVERO ${ }^{4}$, EDUARDO PURGATTO ${ }^{5}$, TÂNIA MISUZU SHIGA ${ }^{6}$, \\ MURILLO DE ALBUQUERQUE REGINA
}

RESUMO-Este trabalho teve como objetivo avaliar o potencial de maturação das cultivares Pinot Noir, Tempranillo, Merlot, Cabernet Sauvignon, Syrah, Chardonnay e Sauvignon Blanc submetidas ao regime de dupla poda, em Cordislândia, região cafeeira do sul de Minas Gerais. As plantas foram submetidas a dois ciclos de produção, um de primavera-verão, compreendido entre agosto e janeiro, e outro ciclo de outonoinverno, entre janeiro e julho. Como parâmetros de qualidade, foram avaliados os diâmetros transversal e longitudinal da baga, acidez, ácidos tartárico e málico, $\mathrm{pH}$, sólidos solúveis, antocianinas, fenólicos totais e os teores de glicose, frutose e sacarose. Todas as variedades apresentaram maiores teores de $\mathrm{pH}$, sólidos solúveis, açúcares, antocianinas e fenólicos totais, e redução nos diâmetros transversal e longitudinal na safra de inverno. A cultivar Syrah destacou-se das demais no conteúdo de antocianinas e fenólicos totais, tanto no verão quanto no inverno, entretanto apresentou o menor conteúdo de açúcares. A alteração do ciclo de produção da videira através da técnica da dupla poda para colheita, no período de inverno, na região cafeeira de Minas Gerais, favorece a maturação dos frutos e melhora consideravelmente a qualidade das uvas para vinificação.

Termos para indexação: Vitis vinifera, maturação, safra, compostos fenólicos, ácidos orgânicos, açúcares.

\section{PHYSICO-CHEMICAL COMPOSITION OF WINE GRAPES BERRIES IN SUMMER AND WINTER GROWING SEASONS}

\begin{abstract}
This work aimed to evaluate some ripening parameters of cultivars Pinot Noir, Tempranillo, Merlot, Cabernet Sauvignon, Syrah, Chardonnay and Sauvignon Blanc submitted to the double-pruning management in Cordislândia, in the coffee region of the south of the state of Minas Gerais. Grapevines were cultivated in two different growing seasons, spring-summer from August to January and autumn-winter from January to July. Quality parameters such as berry transversal and longitudinal diameters, acidity, tartaric and malic acids, $\mathrm{pH}$, soluble solids, anthocyanins, phenolic compounds, glucose, fructose and sucrose were evaluated. All cultivars showed higher $\mathrm{pH}$, soluble solids, sugars, anthocyanins and phenolic compounds levels and lower transversal and longitudinal diameters in winter cycle. Syrah cultivar was stood out with higher anthocyanin and phenolic compounds levels in summer and winter cycles however showed lower reducing sugars levels. The alteration of the production cycle through double-pruning management in order to harvest grapes in the winter in the coffee region of Minas Gerais favors the ripening of the fruits and improves the quality of wine grapes.
\end{abstract}

Index terms: Vitis vinifera, ripening, production cycle, phenolic compounds, organic acids, sugars.

\footnotetext{
1(Trabalho 241-09). Recebido em: 19-10-2009. Aceito para publicação em: 30-04-2010. Trabalho com apoio financeiro da FAPEMIG e CNPq

${ }^{2}$ Engenheira Agrônoma, Doutora em Ciência dos Alimentos, Pesquisadora do Núcleo Tecnológico EPAMIG Uva e Vinho. Avenida Santa Cruz, n 500, Caixa Postal 33, CEP 37780-000, Caldas-MG. E-mail: renata@epamigcaldas.gov.br (autor correspondente)

${ }^{3}$ Aluno de $2^{\circ}$ grau. Núcleo Tecnológico EPAMIG Uva e Vinho. Bolsista BIC Junior FAPEMIG. E-mail: k_mila_pinheiro@hotmail.com ${ }^{4}$ Doutoranda - Universidade Federal de Lavras. Bolsista CAPES - Departamento de Agricultura, caixa postal 3037, CEP 37200-000, Lavras-MG. E-mail: acfavero@yahoo.com.br

${ }^{5}$ Farmacêutico, Doutor em Ciência dos Alimentos, Professor do Departamento de Alimentos e Nutrição Experimental, Faculdade de Ciências Farmacêuticas, Universidade de São Paulo, Caixa Postal 66083, CEP 05315-970, São Paulo-SP. E-mail: epurgatt@usp.br

${ }^{6}$ Farmacêutica, Doutora em Ciência dos Alimentos, Técnica de nível superior do Departamento de Alimentos e Nutrição Experimental, Faculdade de Ciências Farmacêuticas, Universidade de São Paulo. E-mail: tatymish@usp.br

${ }^{7}$ Engenheiro Agrônomo, doutor em Viticultura e Enologia, Pesquisador do Núcleo Tecnológico EPAMIG Uva e Vinho. E-mail: murillo@epamigcaldas.gov.br
} 


\section{INTRODUÇÃO}

Nas regiões do Sul e Sudeste brasileiras, tradicionais regiões produtoras de uvas, a videira é podada em agosto, brota em setembro e floresce em outubro. A maturação inicia-se em dezembro, e a colheita é escalonada entre janeiro e fevereiro, em função da precocidade da variedade. As temperaturas elevadas associadas à presença de água no solo durante o período de vegetação e produção, induzem a um desenvolvimento vegetativo vigoroso, levando o crescimento dos ramos a competir com os frutos pelo acúmulo dos carboidratos gerados pela atividade fotossintética e impedindo a maturação completa das uvas, notadamente da maturação fenólica, importante para elaboração de vinhos encorpados e de guarda, além de aumentar a incidência de doenças fúngicas (GUERRA, 2002).

Nesse sentido, a busca por novas regiões vitícolas que permitam um melhor amadurecimento das uvas tem sido uma constante, o que pode ser verificado pelas iniciativas de plantio de videiras em São Joaquim (SC), na região da Campanha (RS) e nas regiões áridas e semiáridas do Nordeste brasileiro. Entretanto, nas áreas produtoras tropicais, como o Vale do Submédio São Francisco, a falta de amplitude térmica limita o acúmulo dos polifenóis, e os vinhos tintos elaborados nessa região devem ser consumidos jovens devido à sua característica de leveza, estrutura fraca a média e desenvolvimento aromático médio (TONIETTO; CARBONNEAU, 1999).

Uma alternativa é a produção em regiões com condições de temperaturas ambientais situadas entre os extremos de inverno rigoroso e a falta de amplitude térmica do Sul e Nordeste brasileiros. Nesse sentido, o Núcleo Tecnológico EPAMIG Uva e Vinho tem atuado na busca por novas regiões de cultivo no Estado de Minas Gerais orientado nos princípios de que vinhos finos são produzidos em regiões onde a colheita da uva é feita em períodos secos e com temperaturas amenas e contrastantes entre dias e noites, e que existe um zero de vegetação $\left( \pm 10^{\circ} \mathrm{C}\right)$, acima do qual a videira pode vegetar praticamente o ano todo e, dessa forma, seu ciclo é definido em função da data de poda (REGINA et al., 2006).

Os primeiros projetos buscando explorar esses princípios foram instalados no ano de 2001, em Três Corações, e os resultados permitiram comprovar que videiras da cultivar Syrah, podadas em janeiro manifestam um novo ciclo de vegetação e produção normais, com índices de brotação, fertilidade das gemas, maturação e sanidade nitidamente superio- res àqueles observados para essa mesma cultivar durante o verão (AMORIM et al., 2005; FAVERO et al., 2008). Apesar dos dados promissores obtidos para a cultivar Syrah, na região cafeeira de Minas Gerais, ainda não existem relatos na literatura sobre o comportamento de outras cultivares viníferas ao regime de dupla poda.

O objetivo do presente trabalho foi avaliar a maturação de um grupo de cultivares viníferas conduzidas em ciclos de verão e inverno, em Cordislândia, região cafeeira do sul de Minas Gerais.

\section{MATERIAL E MÉTODOS}

Os vinhedos compostos pelas variedades viníferas Cabernet Sauvignon, Tempranillo, Syrah, Merlot, Pinot Noir, Sauvignon Blanc e Chardonnay, enxertadas sobre 1.103 Paulsen, foram instalados em janeiro de 2005, em propriedade particular denominada Fazenda do Porto, localizada no município de Cordislândia, -MG, situado a latitude de $21^{\circ} 47^{\prime} 33^{\prime \prime}$ $\mathrm{S}$, longitude $45^{\circ} 42^{\prime} 03^{\prime \prime} \mathrm{O}$ e altitude de $873 \mathrm{~m}$. O clima de Cordislândia é do tipo Cwa - temperado quente (mesotérmico), com média das temperaturas do mês mais quente superior a $20^{\circ} \mathrm{C}$. O inverno é seco, sendo que, nesse período ocorre, em média, pelo menos um mês com precipitação inferior a $60 \mathrm{~mm}$ (TONIETO et al., 2006). A Figura 1 apresenta os dados de precipitação e temperatura em Cordislândia durante os anos de 2006 e 2007 e a fenologia da videira nos ciclos de primavera/verão e outono/inverno.

As videiras foram plantadas em Latossolo Vermelho, profundo, e com boa drenagem. O solo foi corrigido antes do plantio para $\mathrm{pH} 6,5$, teor de matéria orgânica de 3,5\% e saturação de base de $80 \%$. O solo apresentava ainda $13,7 \mathrm{mg} \mathrm{dm}^{-3}$ de fósforo, $74 \mathrm{mg} \mathrm{dm}^{-3}$

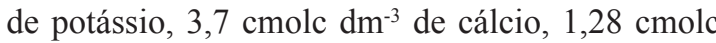
$\mathrm{dm}^{-3}$ de magnésio, $2,11 \mathrm{dag} \mathrm{kg}^{-1}$ de matéria orgânica e $0,3 \mathrm{mg} \mathrm{dm}^{-3}$ de Boro. Após a correção do $\mathrm{pH}$, aplicaram-se em área total $100 \mathrm{~kg}$ de $\mathrm{P}_{2} \mathrm{O}_{5}, 70 \mathrm{~kg}$ de bórax e 15 toneladas de esterco de curral por hectare, que foram em seguida incorporados com gradagem leve. Anualmente, foram ainda adicionados $80 \mathrm{~g}$ de $\mathrm{N}$ e $150 \mathrm{~g}$ de $\mathrm{K}_{2} \mathrm{O}$ por planta em cobertura, distribuídos durante o período compreendido entre brotação e início de maturação dos cachos. Anualmente, e por ocasião da poda de inverno, foram efetuadas as adubações de manutenção em sulco, nas entrelinhas de plantio, com reposição de matéria orgânica e fósforo (FRÁGUAS et al., 2002).

Foi utilizado um delineamento inteiramente casualizado, composto por sete parcelas, uma para cada cultivar, em uma área de 2,0 hectares, distribuídos em 
terreno homogêneo e de mesma exposição para cada parcela. As plantas foram conduzidas em espaldeira, com três fios de arame, no espaçamento $2,70 \mathrm{~m}$ x 1,20 $\mathrm{m}$, num total de 74 linhas de cultivo e 6.172 plantas por parcela. Para cada cultivar, foram escolhidas 400 plantas de porte similar, distribuídas aleatoriamente no interior da parcela.

O manejo da dupla poda empregado foi baseado na técnica já utilizada em Minas Gerais para a produção de uvas de mesa, na região de Pirapora, e já executada para uvas de vinho fino com sucesso, na região de Três Corações, Minas Gerais (AMORIM et al., 2005; FAVERO, 2007). Essa técnica consiste em, primeiramente, executar a poda curta de formação (das varas de produção) em duplo cordão esporonado, no mês de agosto, seguida da aplicação de cianamida hidrogenada (Dormex ${ }^{\circledR}$ ) a $6 \%$ para uniformizar a brotação. A vegetação oriunda dessa poda foi conduzida normalmente, adotando os esquemas de tratamentos fitossanitários contra antracnose e míldio, cultivos e adubações em cobertura, durante o ciclo vegetativo. A colheita foi realizada no mês de janeiro (ciclo de verão). Após a colheita, e um período de descanso de 30 dias, foi realizada uma segunda poda "de produção", também em esporões (duas gemas), seguida da aplicação de Dormex ${ }^{\circledR}$ a $6 \%$, para a formação dos ramos responsáveis pela produção de inverno. Nesse caso, a colheita foi realizada em julho (ciclo de inverno).

Nas duas safras, deixou-se uma carga de 16 gemas por planta, e limitou-se a produção a apenas um cacho por ramo, ou seja, média de 16 cachos por planta, o que traduziu em uma produção de 1,8 a 2,4 kg por planta, ou seja, 5,5 a 7,3 t.ha-1, em função da variação do tamanho do cacho de cada cultivar. Esses índices de produção são compatíveis com o esperado para produção de uvas destinadas à elaboração de vinhos finos de qualidade, e são comparáveis àqueles observados por Favero (2007). Entretanto, variáveis de produção e de produtividade não foram quantificadas, pois, em função da pouca idade do vinhedo, optou-se apenas por controlar a produção, conforme os valores referidos.

Para o acompanhamento da maturação, foram amostradas 225 bagas de cada variedade coletadas nos quatro quadrantes, em cachos distintos, nas plantas situadas nos dois lados das linhas úteis por parcela, em intervalos semanais a partir do final do pintor. As amostras foram mantidas em gelo e levadas ao Laboratório de Análise de Produtos Vegetais do Núcleo Tecnológico-EPAMIG Uva e Vinho, onde foram contadas e pesadas. Foram utilizadas 50 bagas para a determinação dos diâmetros transversal e longitudinal com o auxílio de um paquímetro manual.
As amostras foram separadas em três repetições contendo 70 bagas cada. As bagas de cada repetição foram esmagadas manualmente para extrair o mosto que foi utilizado para as análises de sólidos solúveis ( ${ }^{\circ}$ Brix $)$, em refratômetro digital portátil ATAGO modelo Pal 1; acidez total titulável (meq $\mathrm{L}^{-1}$ ), pela titulação com $\mathrm{NaOH} 0,1 \mathrm{~N}$, utilizando fenolftaleína como indicador; $\mathrm{pH}$ em potenciômetro digital, equipado com eletrodo de vidro (AOAC, 1995).

Os ácidos tartárico e málico foram determinados na fração ácido obtida após passagem do mosto em uma resina de troca aniônica Bio-Rex 5 (Bio Rad Labs) (MCCORD et al., 1984). Uma alíquota de $20 \mu \mathrm{L}$ foi injetada em cromatógrafo líquido Hewlett-Packard, modelo 1100, equipado com coluna SupelcoGel C-610H (Supelco, $30 \mathrm{~cm}$ x $7,8 \mathrm{~mm}$ ) ajustada a uma temperatura de $15{ }^{\circ} \mathrm{C}$, e detector arranjo de diodos (DAD) a $245 \mathrm{~nm}$. Foi realizada uma corrida isocrática a um fluxo de $0,5 \mathrm{~mL}$ $\min ^{-1}$, utilizando solução de ácido fosfórico a $0,5 \%$ como fase móvel. A identificação e a quantificação dos cromatogramas foram baseadas em soluçãopadrão dos ácidos tartárico e málico.

Os teores de glicose, frutose e sacarose foram analisados na fração açúcar obtida após passagem do mosto em resina Bio-Rex 5 (MCCORD et al., 1984). Os açúcares solúveis foram analisados por HPLC-PAD (Dionex, Sunnyvale, CA, USA) em um cromatógrafo DX-500, utilizando uma coluna CarboPac PA1 (Dionex, 4,0 x $250 \mathrm{~mm}$ ) acoplado a um detector de pulso amperométrico, em corrida isotérmica, a $25^{\circ} \mathrm{C}$. Como fase móvel foi, utilizado

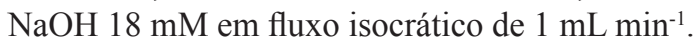

Para a avaliação da maturação fenólica, cascas e sementes de 100 bagas por variedade foram separadas, pesadas, congeladas em nitrogênio líquido e armazenadas a $-20^{\circ} \mathrm{C}$.

Os compostos fenólicos totais foram determinados a partir de $0,5 \mathrm{~g}$ de casca triturada em nitrogênio líquido e homogeneizada em homogeneizador Ultra Turrax (IKA T-18 basic), em solução extratora constituída de metanol acidificado ( $\mathrm{HCl} 1 \%)$. As antocianinas presentes nas variedades tintas foram determinadas pelo método do $\mathrm{pH}$ diferencial (GIUSTI; WROLSTAD, 2000). Os fenólicos totais foram analisados pelo método de Folin-Ciocalteau com base em uma curva-padrão de ácido gálico (AMERINE; OUGH, 1980; BERGQVIST et al., 2001).

As sementes foram imersas na solução alcoólica (metanol HCl 1\%), em proporção correspondente ao volume de mosto das bagas. O volume de mosto foi determinado pela diferença entre o peso da baga e o peso das cascas + sementes (GONZÁLEZ- 
NEVES et al., 2004). As sementes ficaram imersas por $48 \mathrm{~h}$ à temperatura ambiente e ao abrigo da luz com agitações periódicas para a extração dos compostos fenólicos solúveis, que foram determinados pelo método de Folin-Ciocalteau (AMERINE; OUGH, 1980).

As análises físico-químicas foram realizadas em triplicata. Foram comparados dois tratamentos para cada variável (cultivar): ciclo de verão e ciclo de inverno. Os resultados obtidos em cada safra foram submetidos à análise de variância e comparação de médias, pelo teste de Tukey, a 5\% de probabilidade, no programa SAEG versão 9.1.

\section{RESULTADOS E DISCUSSÃO}

Nas condições climáticas de Cordislândia, a diferença de temperatura máxima durante o desenvolvimento e maturação das bagas, nos ciclos de verão (média de $30,3{ }^{\circ} \mathrm{C}$ nos meses de outubro a fevereiro) e inverno (média de $28,8^{\circ} \mathrm{C}$ nos meses de março a julho), é inferior a $4{ }^{\circ} \mathrm{C}$ (Figura 1) e está dentro da faixa considerada ótima para a atividade fotossintética $\left(18{ }^{\circ} \mathrm{C}\right.$ a $33{ }^{\circ} \mathrm{C}$, JACKSON; LOMBARD, 1993), nos dois ciclos. Neste caso, amplitude térmica e precipitação são os principais fatores climáticos responsáveis pelas diferenças na composição das bagas colhidas, nas safras de verão e inverno.

As uvas colhidas em janeiro (ciclo normal) estão sujeitas a elevadas temperaturas e precipitação durante o período de maturação e colheita, o que aumenta a incidência de podridões e resulta em colheita antes da completa maturação das bagas. Nos meses de dezembro a fevereiro, a precipitação observada na área experimental foi de $981 \mathrm{~mm} \mathrm{em}$ 2006 e 837 mm em 2007. A alteração da safra para o período de inverno coincide com significativa redução do índice pluviométrico no período de maturação e colheita. Nas safras de 2006 e 2007, a chuva acumulada durante os meses de abril a julho foi de $69 \mathrm{~mm}$ e 194,9 mm, respectivamente (Figura 1). No ciclo de verão, a temperatura média observada durante a maturação e colheita foi de $30,2^{\circ} \mathrm{C}$ (máxima) e $19,6^{\circ} \mathrm{C}$ (mínima), com amplitude térmica de 10,5 ${ }^{\circ} \mathrm{C}$. No ciclo de inverno, a temperatura máxima observada no período de maturação e colheita foi, em média, de $28,3{ }^{\circ} \mathrm{C}$ e mínima de $11,3{ }^{\circ} \mathrm{C}$, com amplitude térmica de $17^{\circ} \mathrm{C}$ (Figura 1).

Observa-se, na Figura 2, rápida degradação da acidez das bagas cultivadas em ciclo de verão, principalmente nas primeiras semanas de amadurecimento, em função das temperaturas mais elevadas do período. O período de maturação foi maior du- rante o ciclo de inverno, e as uvas apresentaram teor de sólidos solúveis significativamente superior às produzidas em ciclo de verão (Figura 2).

Segundo Jackson e Lombard (1993), temperaturas elevadas aceleram o crescimento e o amadurecimento e resultam em bagas com maior teor de sólidos solúveis, elevado $\mathrm{pH}$, baixa acidez e menor conteúdo de antocianinas e precursores de aroma. Entretanto, os maiores teores de sólidos solúveis observados nas uvas colhidas no inverno devem-se à redução da velocidade de maturação, provavelmente devido à baixa temperatura noturna e menor precipitação, o que permite a permanência dos cachos na planta por um período maior, contribuindo para melhorar a composição das bagas (ROSIER, 2006).

O tamanho das bagas é um dos fatores que determinam a qualidade de uma uva vinífera, notadamente para elaboração de vinhos tintos. Esse conceito baseia-se no fato de que a razão área:volume de bagas aproximadamente esféricas diminui com o aumento do tamanho da baga. Como as antocianinas e outros compostos fenólicos se localizam na casca, bagas menores apresentam maior relação soluto:solvente e, consequentemente, maior probabilidade de extração durante a maceração (CONDE et al., 2007). Os cachos colhidos na safra de inverno apresentaram bagas com peso e tamanho inferiores aos da safra de verão (Tabela 1).

O tamanho da baga é influenciado pela disponibilidade hídrica do solo. Déficit hídrico geralmente resulta em bagas menores e modifica a composição do fruto (KENNEDY et al., 2002). No ciclo de verão, devido ao excesso de chuva durante o amadurecimento, uma fina superfície úmida cobre as bagas, principalmente em cachos compactos, e pode ser responsável pelo aumento do diâmetro por absorção de água através da casca (BLOUIN; GUIMBERTEAU, 2004). O maior tamanho das bagas em ciclo de verão também pode ser consequência do excesso de chuva entre o florescimento e a coloração das bagas. Ojeda et al. (2001) afirmaram que a restrição de água nestes estádios fenológicos afeta o crescimento celular e reduz o volume da célula.

A colheita no inverno aumentou significativamente o teor de sólidos solúveis $\left({ }^{\circ} \mathrm{Brix}\right)$ e açúcares redutores (glicose e frutose) no mosto. Sacarose não foi detectada (Tabela 2). O açúcar presente no mosto é sintetizado nas folhas pela fotossíntese e transportado até as bagas na forma de sacarose via floema (DAVIES; ROBINSON, 1996). A sacarose sofre a ação de invertases localizadas na parede celular, citoplasma e vacúolo, sendo hidrolisadas a glicose e a frutose (CONDE et al., 2007). No início da coloração das bagas, entretanto, 
ocorre perda da compartimentalização do tecido do mesocarpo dos frutos, e um processo não metabólico, a evapotranspiração, passa a promover o acúmulo de açúcares durante o amadurecimento (DREIER et al., 2000). Neste caso, numa mesma condição climática, bagas menores apresentam maior concentração de açúcar devido à relação superfície:volume mais favorável à desidratação.

Favero (2007) avaliou a fotossíntese de videiras da cultivar Syrah em ciclo de verão e inverno, em Três Corações (MG), e constatou taxas fotossintéticas inferiores no ciclo de inverno. A autora atribuiu o aumento na concentração de sólidos solúveis em ciclo de inverno $\left(20,6^{\circ}\right.$ Brix contra 17,4 ${ }^{\circ}$ Brix no verão) à redução do diâmetro das bagas e menor ocorrência de chuvas.

Roby et al. (2004) avaliaram o efeito do tamanho das bagas e déficit hídrico na composição de uvas Cabernet Sauvignon. Os autores observaram que o acúmulo de sólidos solúveis depende do tamanho das bagas e é favorecido por estresse hídrico moderado (entre -1,2 e -1,4 MPa). Em condições de estresse hídrico, o aumento no teor de sólidos solúveis é decorrente da concentração de açúcares como consequência do menor tamanho da baga. Neste caso, as bagas são menores devido à menor disponibilidade de água para a elongação celular (ESTEBAN et al., 2002).

Esteban et al. (2002) observaram relação estatisticamente significativa entre a acidez total e o $\mathrm{pH}$. Durante o amadurecimento, o $\mathrm{pH}$ aumenta de forma linear, enquanto a acidez total decresce exponencialmente no mesmo período, em decorrência, principalmente, da redução do ácido málico. Para uma mesma concentração de acidez total, o pH é menor em condições de maior disponibilidade hídrica. $\mathrm{O}$ valor de $\mathrm{pH}$ é dependente, além da acidez total, das concentrações relativas de ácidos málico e tartárico e do grau de formação de sais ácidos, que, por sua vez, depende do conteúdo de potássio na baga.

As uvas cultivadas em ciclo de inverno apresentaram maiores valores de $\mathrm{pH}$ e acidez total superior ou estatisticamente semelhante aos valores obtidos nas bagas colhidas no verão (Tabela 3). Segundo Jackson e Lombard (1993), noites frias, associadas a elevada temperatura durante o dia, reduzem o pH e a degradação dos ácidos orgânicos quando comparada a regiões de cultivo com dias e noites quentes. Neste experimento, o maior valor de $\mathrm{pH}$ observado no inverno pode ser resultado da menor disponibilidade hídrica (ESTEBAN et al., 2002).

Nos estágios iniciais do desenvolvimento da baga, o ácido málico predomina sobre o tartárico, enquanto essa condição inverte nos estágios finais do crescimento. A concentração de tartárico pode ser até 4 vezes superior à de málico na colheita. $\mathrm{O}$ decréscimo acentuado no conteúdo de ácido málico durante o amadurecimento ocorre não apenas devido ao processo de diluição pelo aumento do peso da baga, mas também devido ao seu alto catabolismo. Além disso, condições de déficit hídrico favorecem o catabolismo do ácido málico (ESTEBAN et al., 2002).

Os teores de ácidos málico e tartárico foram superiores na safra de inverno para as cultivares Merlot, Syrah, Chardonnay e Sauvignon Blanc e semelhantes aos da safra de verão para as cultivares Pinot Noir, Tempranillo e Cabernet Sauvignon (Tabela 3). Dados obtidos com diferentes cultivares de uvas indicam redução do teor de ácido málico em função, principalmente, da temperatura da baga (BERGQVIST et al., 2001; CONDE et al., 2007). De acordo com esses autores, à medida que a temperatura aumenta, as necessidades energéticas crescem e, para manter a produção de energia, a célula recorre ao ácido málico armazenado através de um aumento de atividade da enzima málica. Dessa forma, uvas colhidas em regiões frias normalmente são mais ricas em ácido málico do que as de regiões quentes.

A alteração da safra aumentou consideravelmente o conteúdo de compostos fenólicos na casca das bagas colhidas no inverno (Tabela 4). Das cultivares analisadas, 'Syrah' apresentou o maior conteúdo de compostos fenólicos (em média $24 \mathrm{mg} / \mathrm{g}$ ), seguida por 'Tempranillo' e 'Cabernet Sauvignon' (20 mg/g), 'Pinot' e 'Merlot' (14 mg/g) e 'Chardonnay' e 'Sauvignon Blanc' (6 $\mathrm{mg} / \mathrm{g}$ ). Os compostos fenólicos presentes na casca conferem características organolépticas positivas ao vinho e são normalmente encontrados em pequenas quantidades nas variedades brancas.

$\mathrm{O}$ teor de antocianinas também aumentou consideravelmente nas bagas colhidas no inverno, $\mathrm{o}$ que, juntamente com o teor de compostos fenólicos indica avanço da maturação, independentemente do tamanho das bagas. Assim como observado para os compostos fenólicos da casca, o maior teor de antocianinas foi obtido em bagas de 'Syrah', e o menor, em 'Pinot' (Tabela 4).

Os compostos fenólicos nas sementes foram ligeiramente superiores nas bagas colhidas no inverno. A cultivar Pinot destacou-se por apresentar teores significativamente mais elevados que as demais cultivares (Tabela 4).

Vários estudos mostram que amadurecimento em condições de baixa temperatura noturna favorece a síntese de antocianinas e precursores de aroma 
(JACKSON; LOMBARD, 1993; BERGQVIST et al., 2001; SPAYD et al., 2002; DELOIRE et al., 2004; TONIETTO; CARBONNEAU, 2004; MORI et al., 2005; KOSHITA et al., 2007). Os taninos das sementes diminuem durante o amadurecimento. Essa redução acompanha o escurecimento das sementes e ocorre possivelmente devido à oxidação dos taninos
(ADAMS, 2006)

A cultivar Pinot é muito sensível à podridão e, por isso, não é possível manter as bagas no campo por tempo suficiente para completar o amadurecimento. $\mathrm{Na}$ safra de inverno, o ciclo foi mais longo e, por isso, as bagas apresentaram melhor qualidade em relação à safra de verão.

TABELA 1 - Composição física das bagas de sete cultivares viníferas colhidas na safra de verão e inverno de 2007 em Cordislândia (MG).

\begin{tabular}{|c|c|c|c|c|c|c|}
\hline \multirow[t]{2}{*}{ Variedade } & \multicolumn{2}{|c|}{$\begin{array}{c}\text { Diâmetro } \\
\text { transversal }(\mathrm{mm})\end{array}$} & \multicolumn{2}{|c|}{$\begin{array}{c}\text { Diâmetro } \\
\text { longitudinal }(\mathrm{mm})\end{array}$} & \multicolumn{2}{|c|}{ Peso (g) } \\
\hline & verão & inverno & verão & inverno & verão & inverno \\
\hline Pinot Noir & $13,7 \pm 1,0 \mathrm{~A}$ & $13,2 \pm 1,1 \mathrm{~B}$ & $14,4 \pm 1,2 \mathrm{~A}$ & $13,5 \pm 1,1 \mathrm{~B}$ & $1,5 \pm 0,10 \mathrm{~A}$ & $1,0 \pm 0,01 \mathrm{~B}$ \\
\hline Tempranillo & $16,2 \pm 1,4 \mathrm{~A}$ & $15,0 \pm 1,0 \mathrm{~B}$ & $16,0 \pm 1,2 \mathrm{~A}$ & $15,1 \pm 1,1 \mathrm{~B}$ & $2,5 \pm 0,05 \mathrm{~A}$ & $1,6 \pm 0,01 \mathrm{~B}$ \\
\hline Merlot & $14,4 \pm 0,9 \mathrm{~A}$ & $12,2 \pm 0,9 \mathrm{~B}$ & $14,7 \pm 0,9 \mathrm{~A}$ & $12,5 \pm 1,0 \mathrm{~B}$ & $1,8 \pm 0,03 \mathrm{~A}$ & $1,2 \pm 0,02 \mathrm{~B}$ \\
\hline Cabernet Sauvignon & $14,8 \pm 1,1 \mathrm{~A}$ & $12,5 \pm 0,9 \mathrm{~B}$ & $15,7 \pm 1,2 \mathrm{~A}$ & $12,9 \pm 0,9 \mathrm{~B}$ & $2,0 \pm 0 \mathrm{~A}$ & $1,1 \pm 0,01 \mathrm{~B}$ \\
\hline Syrah & $14,8 \pm 1,0 \mathrm{~A}$ & $13,0 \pm 1,0 \mathrm{~B}$ & $16,1 \pm 1,2 \mathrm{~A}$ & $13,5 \pm 1,0 \mathrm{~B}$ & $2,1 \pm 0,03 \mathrm{~A}$ & $1,3 \pm 0,01 \mathrm{~B}$ \\
\hline Chardonnay & $14,3 \pm 1,1 \mathrm{~A}$ & $13,3 \pm 0,8 \mathrm{~B}$ & $14,8 \pm 1,2 \mathrm{~A}$ & $13,4 \pm 0,7 \mathrm{~B}$ & $1,8 \pm 0,01 \mathrm{~A}$ & $1,2 \pm 0,01 \mathrm{~B}$ \\
\hline Sauvignon blanc & $15,5 \pm 1,2 \mathrm{~A}$ & $13,1 \pm 0,9 \mathrm{~B}$ & $16,7 \pm 1,1 \mathrm{~A}$ & $13,9 \pm 1,0 \mathrm{~B}$ & $2,3 \pm 0,03 \mathrm{~A}$ & $1,0 \pm 0,02 \mathrm{~B}$ \\
\hline
\end{tabular}

Dados representam a média de três repetições \pm desvio-padrão.

Letras diferentes entre colunas (verão e inverno) diferem entre si, pelo teste de Tukey, a $5 \%$ de probabilidade.

TABELA 2 - Teores de sólidos solúveis e açúcares nas bagas de sete cultivares viníferas colhidas na safra de verão e inverno de 2007 em Cordislândia (MG).

\begin{tabular}{|c|c|c|c|c|c|c|c|c|}
\hline \multirow[t]{2}{*}{ Variedade } & \multicolumn{2}{|c|}{$\begin{array}{l}\text { Sólidos solúveis } \\
\quad\left({ }^{\circ} \text { Brix }\right)\end{array}$} & \multicolumn{2}{|c|}{$\begin{array}{l}\text { Glicose } \\
\left(\mathrm{g} \mathrm{L}^{-1}\right)\end{array}$} & \multicolumn{2}{|c|}{$\begin{array}{l}\text { Frutose } \\
\left(\mathrm{g} \mathrm{L}^{-1}\right)\end{array}$} & \multicolumn{2}{|c|}{$\begin{array}{c}\text { Relação } \\
\text { glicose: } \\
\text { frutose }\end{array}$} \\
\hline & verão & inverno & verão & inverno & verão & inverno & verão & inverno \\
\hline Pinot Noir & $16,1 \pm 0,4 \mathrm{~B}$ & $23,0 \pm 0,3 \mathrm{~A}$ & $74,8 \pm 5,7 \mathrm{~B}$ & $116,9 \pm 14,6 \mathrm{~A}$ & $69,5 \pm 4,6 \mathrm{~B}$ & $111,3 \pm 14,1 \mathrm{~A}$ & 1,08 & 1,05 \\
\hline Tempranillo & $17,8 \pm 0,1 \mathrm{~B}$ & $21,3 \pm 0,2 \mathrm{~A}$ & $88,5 \pm 1,2 \mathrm{~B}$ & $96,2 \pm 2,3 \mathrm{~A}$ & $89,3 \pm 1,1 \mathrm{~B}$ & $106,2 \pm 1,5 \mathrm{~A}$ & 0,99 & 0,91 \\
\hline Merlot & $17,7 \pm 0,1 \mathrm{~B}$ & $20,8 \pm 0,35 \mathrm{~A}$ & $83,6 \pm 2,0 \mathrm{~B}$ & $99,9 \pm 4,7 \mathrm{~A}$ & $83,1 \pm 1,8 \mathrm{~B}$ & $101,8 \pm 4,8 \mathrm{~A}$ & 1,01 & 0,98 \\
\hline $\begin{array}{l}\text { Cabernet } \\
\text { Sauvignon }\end{array}$ & $14,0 \pm 0,4 \mathrm{~B}$ & $20,4 \pm 0,4 \mathrm{~A}$ & $63,1 \pm 3,9 \mathrm{~B}$ & $105,9 \pm 15,4 \mathrm{~A}$ & $57,4 \pm 3,2 \mathrm{~B}$ & $104,3 \pm 17,7 \mathrm{~A}$ & 1,10 & 1,02 \\
\hline Syrah & $14,9 \pm 0,2 \mathrm{~B}$ & $18,2 \pm 0,1 \mathrm{~A}$ & $67,8 \pm 6,3 \mathrm{~B}$ & $96,2 \pm 5,9 \mathrm{~A}$ & $65,4 \pm 6,2 \mathrm{~B}$ & $91,2 \pm 8,3 \mathrm{~A}$ & 1,04 & 1,05 \\
\hline Chardonnay & $16,9 \pm 0,1 \mathrm{~B}$ & $22,7 \pm 0,3 \mathrm{~A}$ & $79,7 \pm 9,9 \mathrm{~B}$ & $119,1 \pm 5,1 \mathrm{~A}$ & $80,7 \pm 9,6 \mathrm{~B}$ & $122,5 \pm 4,5 \mathrm{~A}$ & 0,99 & 0,97 \\
\hline $\begin{array}{l}\text { Sauvignon } \\
\text { blanc }\end{array}$ & $17,8 \pm 0,1 \mathrm{~B}$ & $25,2 \pm 0,4 \mathrm{~A}$ & $78,7 \pm 15,4 \mathrm{~B}$ & $140,5 \pm 4,2 \mathrm{~A}$ & $74,0 \pm 14,4 \mathrm{~B}$ & $128,8 \pm 3,6 \mathrm{~A}$ & 1,06 & 1,09 \\
\hline
\end{tabular}

Dados representam a média de três repetições \pm desvio-padrão.

Letras diferentes entre colunas (verão e inverno) diferem entre si, pelo teste de Tukey, a 5\% de probabilidade. 
TABELA 3 - Teores de pH e acidez no mosto de sete cultivares viníferas colhidas na safra de verão e inverno de 2007 em Cordislândia (MG).

\begin{tabular}{|c|c|c|c|c|c|c|c|c|}
\hline \multirow[b]{2}{*}{ Variedade } & \multicolumn{2}{|c|}{$\mathrm{pH}$} & \multicolumn{2}{|c|}{ Acidez $($ meq L-1) } & \multicolumn{2}{|c|}{ Tartárico $\left(\mathrm{g} \mathrm{L}^{-1}\right)$} & \multicolumn{2}{|c|}{ Málico $\left(\mathrm{g} \mathrm{L}^{-1}\right)$} \\
\hline & verão & inverno & verão & inverno & verão & inverno & verão & inverno \\
\hline Pinot Noir & $3,3 \pm 0,02 \mathrm{~B}$ & $3,6 \pm 0,03 \mathrm{~A}$ & $122,0 \pm 4,4 \mathrm{~A}$ & $114,0 \pm 2,0 \mathrm{~B}$ & $5,6 \pm 0,4 \mathrm{~A}$ & $5,5 \pm 0,5 \mathrm{~A}$ & $4,7 \pm 0,1 \mathrm{~A}$ & $4,4 \pm 0,2 \mathrm{~A}$ \\
\hline Tempranillo & $3,4 \pm 0,01 \mathrm{~B}$ & $3,6 \pm 0,01 \mathrm{~A}$ & $95,3 \pm 0,6 \mathrm{~A}$ & $95,7 \pm 0,6 \mathrm{~A}$ & $4,5 \pm 0,4 \mathrm{~A}$ & $3,4 \pm 0,4 \mathrm{~B}$ & $3,9 \pm 0,3 \mathrm{~A}$ & $3,7 \pm 0,2 \mathrm{~A}$ \\
\hline Merlot & $3,5 \pm 0,01 \mathrm{~B}$ & $3,6 \pm 0,02 \mathrm{~A}$ & $92,1 \pm 0 \mathrm{~A}$ & $92,3 \pm 2,5 \mathrm{~A}$ & $5,3 \pm 0,6 \mathrm{~B}$ & $7,1 \pm 0,3 \mathrm{~A}$ & $2,5 \pm 0,4 \mathrm{~B}$ & $3,6 \pm 0,4 \mathrm{~A}$ \\
\hline $\begin{array}{l}\text { Cabernet } \\
\text { Sauvignon }\end{array}$ & $3,3 \pm 0,02 \mathrm{~B}$ & $3,4 \pm 0,02 \mathrm{~A}$ & $124,3 \pm 8,1 \mathrm{~B}$ & $138,7 \pm 5,5 \mathrm{~A}$ & $6,1 \pm 0,2 \mathrm{~A}$ & $6,7 \pm 0,3 \mathrm{~A}$ & $4,6 \pm 0,3 \mathrm{~A}$ & $5,0 \pm 0,2 \mathrm{~A}$ \\
\hline Syrah & $3,4 \pm 0,02 \mathrm{~B}$ & $3,6 \pm 0,02 \mathrm{~A}$ & $86,7 \pm 1,5 \mathrm{~B}$ & $98,0 \pm 2,6 \mathrm{~A}$ & $5,0 \pm 0,4 \mathrm{~A}$ & $5,6 \pm 0,2 \mathrm{~A}$ & $2,6 \pm 0,3 \mathrm{~B}$ & $5,7 \pm 0,3 \mathrm{~A}$ \\
\hline Chardonnay & $3,4 \pm 0,01 \mathrm{~B}$ & $3,6 \pm 0,02 \mathrm{~A}$ & $98,7 \pm 2,5 \mathrm{~A}$ & $94,0 \pm 1,0 \mathrm{~A}$ & $4,9 \pm 1,0 \mathrm{~B}$ & $6,1 \pm 0,2 \mathrm{~A}$ & $2,9 \pm 0,5 \mathrm{~B}$ & $3,6 \pm 0,3 \mathrm{~A}$ \\
\hline $\begin{array}{l}\text { Sauvignon } \\
\text { blanc }\end{array}$ & $3,3 \pm 0 \mathrm{~B}$ & $3,4 \pm 0,02 \mathrm{~A}$ & $108,3 \pm 0,6 \mathrm{~A}$ & $106,5 \pm 1,3 \mathrm{~A}$ & $5,5 \pm 0,8 \mathrm{~B}$ & $8,9 \pm 0,5 \mathrm{~A}$ & $2,9 \pm 0,4 \mathrm{~A}$ & $3,2 \pm 0,3 \mathrm{~A}$ \\
\hline
\end{tabular}

Dados representam a média de três repetições \pm desvio-padrão.

Letras diferentes entre colunas (verão e inverno) diferem entre si, pelo teste de Tukey, a $5 \%$ de probabilidade.

TABELA 4- Compostos fenólicos nas bagas de sete cultivares viníferas colhidas na safra de verão e inverno de 2007 em Cordislândia (MG).

\begin{tabular}{|c|c|c|c|c|c|c|}
\hline \multirow[t]{2}{*}{ Variedade } & \multicolumn{2}{|c|}{$\begin{array}{l}\text { Antocianinas } \\
\text { (mg malvidina } \\
\left.\mathrm{g}(\text { casca })^{-1}\right)\end{array}$} & \multicolumn{2}{|c|}{$\begin{array}{c}\text { Fenólicos } \\
\left(\mathrm{mg} \text { ac.gálico } \mathrm{g}(\text { casca })^{-1}\right)\end{array}$} & \multicolumn{2}{|c|}{$\begin{array}{c}\text { Fenólicos } \\
\left(\mathrm{mg} \text { ac.gálico } \mathrm{g}(\text { semente })^{-1}\right)\end{array}$} \\
\hline & verão & inverno & verão & inverno & verão & inverno \\
\hline Pinot Noir & $2,1 \pm 0,1 \mathrm{~B}$ & $2,6 \pm 0,1 \mathrm{~A}$ & $11,6 \pm 0,5 \mathrm{~B}$ & $14,4 \pm 0,5 \mathrm{~A}$ & $120,9 \pm 4,5 \mathrm{~A}$ & $139,4 \pm 6,8 \mathrm{~A}$ \\
\hline Tempranillo & $2,7 \pm 0,2 \mathrm{~B}$ & $4,7 \pm 0,2 \mathrm{~A}$ & $10,3 \pm 0,6 \mathrm{~B}$ & $19,8 \pm 1,1 \mathrm{~A}$ & $72,0 \pm 1,4 \mathrm{~A}$ & $61,3 \pm 5,3 \mathrm{~A}$ \\
\hline Merlot & $3,5 \pm 0,1 \mathrm{~B}$ & $4,3 \pm 0,1 \mathrm{~A}$ & $12,1 \pm 0,6 \mathrm{~B}$ & $13,9 \pm 0,9 \mathrm{~A}$ & $78,7 \pm 4,2 \mathrm{~B}$ & $95,1 \pm 11,4 \mathrm{~A}$ \\
\hline $\begin{array}{l}\text { Cabernet } \\
\text { Sauvignon }\end{array}$ & $2,2 \pm 0,1 \mathrm{~B}$ & $6,2 \pm 0,4 \mathrm{~A}$ & $10,6 \pm 0,7 \mathrm{~B}$ & $19,7 \pm 1,4 \mathrm{~A}$ & $58,9 \pm 5,8 \mathrm{~B}$ & $93,0 \pm 5,7 \mathrm{~A}$ \\
\hline Syrah & $7,4 \pm 0,1 \mathrm{~B}$ & $8,6 \pm 0,3 \mathrm{~A}$ & $22,8 \pm 0,5 \mathrm{~B}$ & $24,4 \pm 2,0 \mathrm{~A}$ & $74,9 \pm 2,1 \mathrm{~A}$ & $70,3 \pm 6,2 \mathrm{~A}$ \\
\hline Chardonnay & & & $6,7 \pm 0,2 \mathrm{~B}$ & $6,7 \pm 0,2 \mathrm{~A}$ & $74,2 \pm 4,5 \mathrm{~A}$ & $75,7 \pm 2,5 \mathrm{~A}$ \\
\hline $\begin{array}{l}\text { Sauvignon } \\
\text { blanc }\end{array}$ & & & $4,3 \pm 0,1 \mathrm{~B}$ & $6,8 \pm 0,6 \mathrm{~A}$ & $62,2 \pm 2,9 \mathrm{~A}$ & $65,8 \pm 4,6 \mathrm{~A}$ \\
\hline
\end{tabular}

Dados representam a média de três repetições \pm desvio-padrão.

Letras diferentes entre colunas (verão e inverno) diferem entre si, pelo teste de Tukey, a 5\% de probabilidade. 

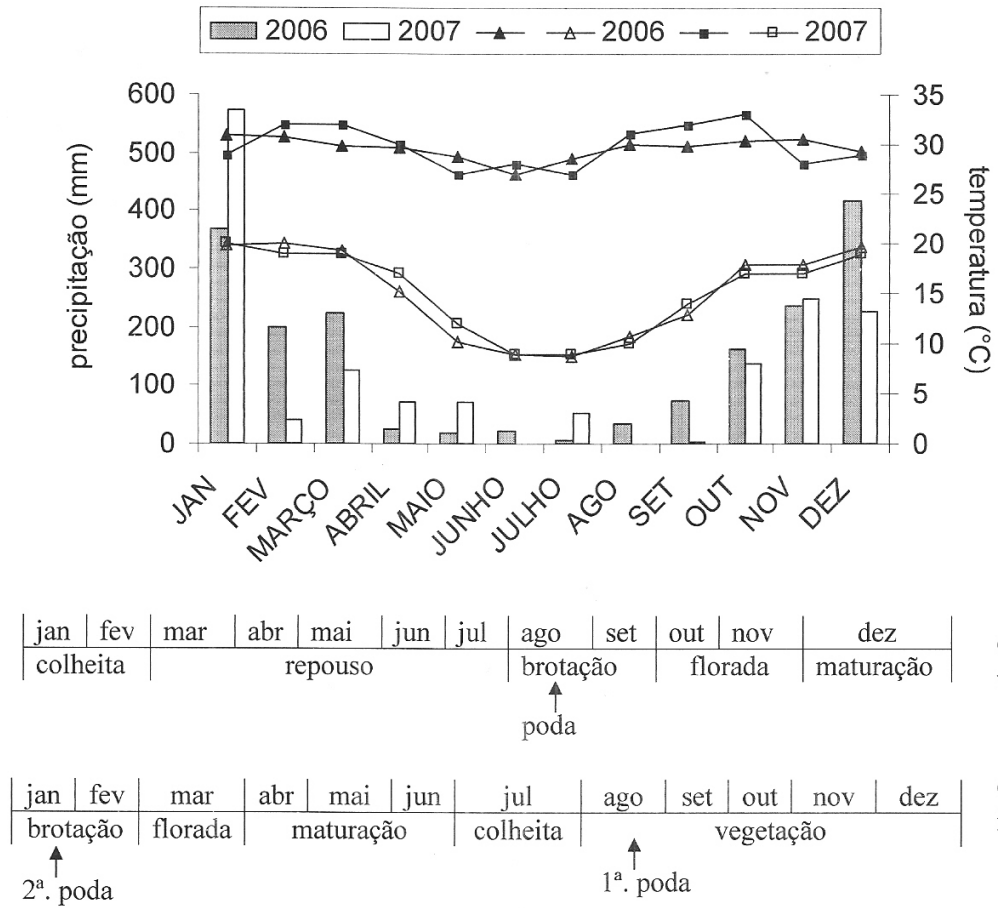

Ciclo primaveraverão (ago a jan)

Ciclo outonoinverno (jan a jul)

FIGURA 1- Fenologia da videira nos ciclos de verão e inverno, precipitação e temperaturas máxima e mínima observadas durante o ano em Cordislândia (MG). Dados representam valores médios mensais observados nos anos de 2006 e 2007. 

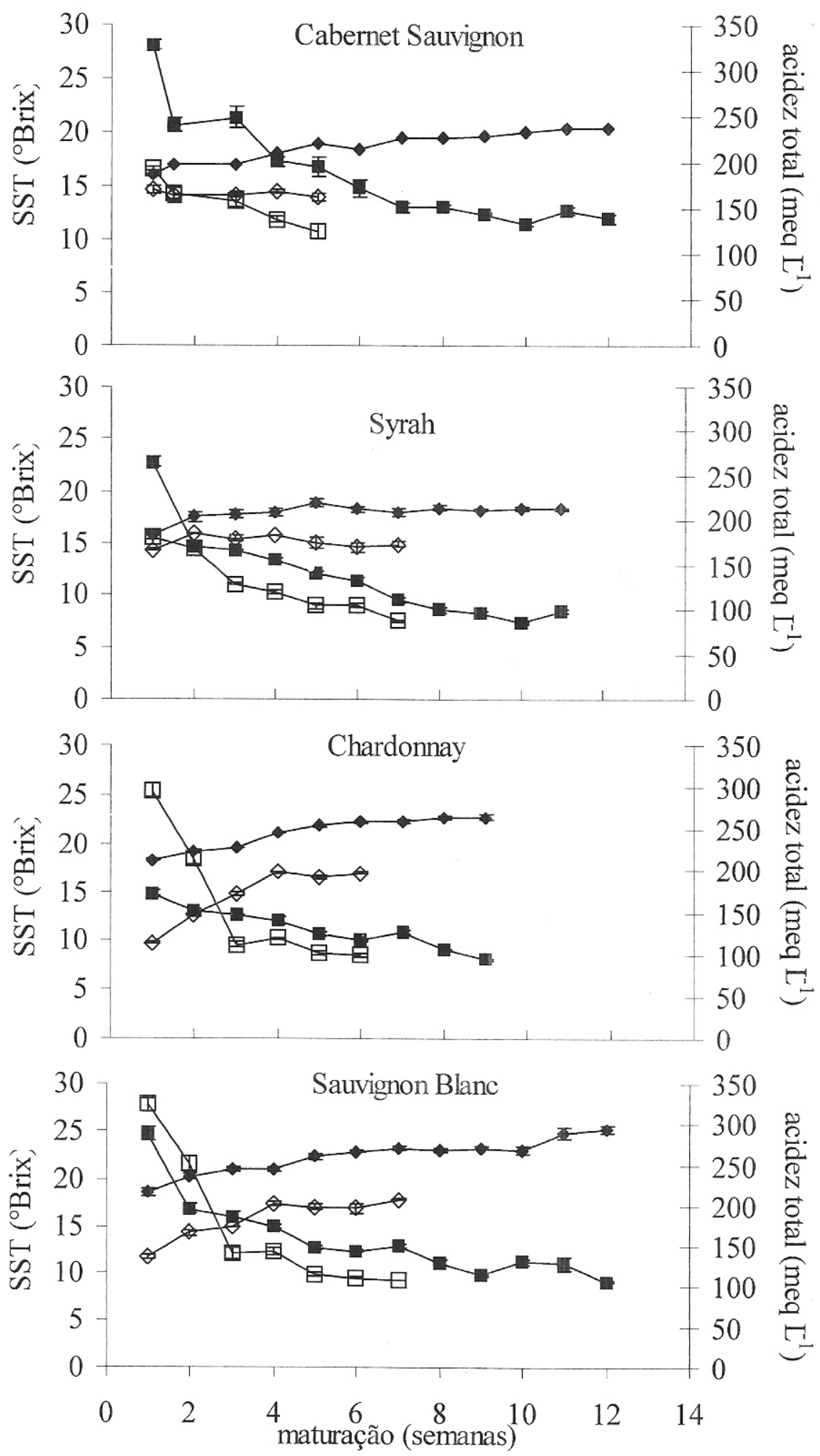

FIGURA 2 - Evolução nos teores de sólidos solúveis (- - e acidez total (—-—) durante o amadurecimento de duas cultivares tintas (Cabernet Sauvignon e Syrah) e brancas (Sauvignon Blanc e Chardonnay), em ciclos de verão e inverno, na região cafeeira de Minas Gerais. Símbolo cheio indica a safra de inverno e símbolo vazio a safra de verão). 


\section{CONCLUSÕES}

1-Todas as variedades avaliadas apresentam maiores valores de $\mathrm{pH}$, sólidos solúveis, açúcares nas bagas, antocianinas e fenólicos totais nas cascas e sementes, e redução nos diâmetros transversal e longitudinal das bagas na safra de inverno.

2-Bagas colhidas na safra de inverno apresentam maior teor de ácido málico no mosto.

3-'Syrah' destaca-se das demais no conteúdo de antocianinas e fenólicos totais nas cascas, tanto no verão quanto no inverno, entretanto apresenta o menor conteúdo de açúcares.

4-A alteração do ciclo de produção para colheita nos meses mais secos do ano contribui para o avanço da maturação das bagas e a melhoria da qualidade do mosto, expresso principalmente pelo teor de açúcar, acidez e compostos fenólicos.

\section{AGRADECIMENTOS}

À Fundação de Amparo à Pesquisa do Estado de Minas Gerais, ao Conselho Nacional de Desenvolvimento Científico e Tecnológico e à Coordenação de Aperfeiçoamento de Pessoal de Nível Superior, pelo auxílio financeiro e concessão de bolsas; à Fazenda do Porto, por ceder a área experimental e pessoal para a manutenção do vinhedo.

\section{REFERÊNCIAS}

ADAMS, D.O. Phenolics and ripening in grape berries. American Journal of Enolology and Viticulture, Davis, v.57, p.249-256, 2006.

AMERINE, M.A.; OUGH, C.S. Methods for analysis of musts and wines. New York: John Wiley \& Sons, 1980. 341p.

AMORIM, D.A.; FAVERO, A.C.; REGINA, M.A. Produção extemporânea da videira, cultivar Syrah, nas condições do sul de Minas Gerais. Revista Brasileira de Fruticultura, Jaboticabal, v.27, n.2, p.327-331, 2005.

AOAC. Official methods of analysis. $16^{\text {th }}$ ed. Washington, DC: Association of Official Analytical Chemists. 1995.
BERGQVIST, J.; DOKOOZLIAN, N.; EBISUDA, N. Sunlight exposure and temperature effects on berry growth and composition of Cabernet Sauvignon and Grenache in the Central San Joaquin Valley of California. American Journal of Enology and Viticulture, Davis, v.52, n.1, p.1-7, 2001.

BLOUIN, J.; GUIMBERTEAU, G. Maduración y madurez de la uva. Madrid: Mundi-Prensa, 2004. $151 \mathrm{p}$.

CONDE, C.; SILVA, P.; FONTES, N.; DIAS, A.C.P.; TAVARES, R.M.; SOUSA, M.J.; AGASSE, A.; DELROT, S.; GERÓS, H. Biochemical changes throughout grape berry development and fruit and wine quality. Food, London, v.1, n.1, p.1-22, 2007.

DAVIS, C.; ROBINSON, S.P. Sugar accumulation in grape berries. Plant Physiology, Bethesda, v.111, p. 275-283, 1996

DELOIRE, A.A.; CARBONNEAU, A.; WANG, Z.P.; OJEDA, H. Vine and water: a short review. Journal International des Sciences de la Vigne et du Vin, Bordeaux, v.38, p.1-13, 2004.

DREIER, L.P.; STOLL, G.S.; RUFFNER, H.P. Berry ripening and evapotranspiration in Vitis vinifera $\mathrm{L}$. American Journal of Enology and Viticulture, Davis, v.51, n.4, p.340-346, 2000.

ESTEBAN, M.A.; VILLANUEVA, M.J.; LISSARRAGUE, J.R. Relationships between different berry components in Tempranillo (Vitis vinifera L.) grapes from irrigated and non-irrigated vines during ripening. Journal of the Science of Food and Agriculture, Chichester, v.82, p.1136-1146, 2002.

FAVERO, A.C. Viabilidade de produção da videira Syrah, em ciclos de verão e inverno no sul de Minas Gerais. Lavras, 2007. 114 f. Dissertação (Mestrado) - Universidade Federal de Lavra, Lavras, 2007.

FAVERO, A.C.; AMORIM, D.A.; MOTA, R.V.; SOARES, A.M.; REGINA, M.A. Viabilidade de Produção da videira 'Syrah'em ciclo de outono inverno na região Sul de Minas Gerais. Revista Brasileira de Fruticultura, Jaboticabal, v.30, n.3, p.685-690, 2008. 
FRAGUAS, J.C.; REGINA, M.A.; ALVARENGA, A.A.; ANTUNES, L.E.C.; FADINI, M.A.M. Calagem e adubação para a videira e fruteiras de clima temperado. Belo Horizonte: EPAMIG, 2002. 44p. (Boletim Técnico, 65).

GIUSTI, M.M.; WROSLTAD, R.E. Characterization and measurement of anthocyanins by uv-visible spectroscopy. current protocols in food analytical chemistry. New York: John Willey \& Sons, 2000.

GONZÁLEZ-NEVES, G.; CHARAMELO, D.; BALADO, J.; BARREIRO, L.; BOCHICCHIO, R.; GATTO, G.; GIL, G.; TESSORE, A.; CARBONNEAU, A.; MOUTOUNET, M. Phenolic potencial of Tannat, Cabernet Sauvignon and Merlot grapes and their correspondence with wine composition. Analytica Chimica Acta, Amsterdam, v.513, p.191196, 2004.

GUERRA, C.C. Maturação da uva e condução da vinificação para a elaboração de vinhos finos. In: REGINA, M.A. (Coord.). Viticultura e enologia: atualizando conceitos. Caldas: EPAMIG/FECD, 2002. p.179-192.

JACKSON, D.I.; LOMBARD, P.B. Environmental and management practices affecting grape composition and wine quality: a review. American Journal of Enology and Viticulture, Davis, v.44, n.4, p.409430, 1993.

KENNEDY, J.A.; MATTHEWS, M.A.; WATERHOUSE, A.L. Effect of maturity and vine water status on grape skin and wine flavonoids. American Journal of Enology and Viticulture, Davis, v.53, p.268-274, 2002.

KOSHITA, Y.; ASAKURA, T.; FUKUDA, H.; TSUCHIDA, Y. Nighttime temperature treatment of fruit cluster of 'Aki Queen' grapes during maturation and its effect on the skin color and abscisic acid content. Vitis, Siebeldingen, v.46, p.208-209, 2007.

McCORD, J.D.; TROUSDALE, E.; RYU, D.D.Y. An improved sample preparation procedure for the analysis of major organic compounds in grape must and wine by high performance liquid chromatography. American Journal of Enology and Viticulture, Davis, v.35, p.28-29, 1984.
MORI, K.; SAITO, H.; GOT-YAMAMOTO, N.; KITAYAMA, M.; KOBAYASHI, S.; SUGAYA, S.; GEMMA, H.; HASHIZUME, K. Effects of abscisic acid treatment and night temperatures on anthocyanin composition in Pinot noir grapes. Vitis, Siebeldingen, v.44, p.161-165, 2005.

OJEDA, H.; DELOIRE, A.; CARBONNEAU, A. Influence of water deficits on grape berry growth. Vitis, Siebeldingen, v.40, p.141-145, 2001.

REGINA, M.A.; AMORIM, D.A.; FAVERO, A.C.; MOTA, R.V.; RODRIGUES, D.J. Novos polos vitícolas para produção de vinhos finos em Minas Gerais. Informe Agropecuário, Belo Horizonte, v.27, n.234, p.111-118, 2006.

ROBY, G.; HARBERTSON, J.F.; ADAMS, D.A.; MATTHEWS, M.A. Berry size and vine water deficits as factors in winegrape composition: anthocyanins and tannins. Australian Journal of Grape and Wine Research, Adelaide, v.10, p.100-107, 2004.

ROSIER, J.P. Vinhos de altitude: característica e potencial na produção de vinhos finos brasileiros. Informe Agropecuário, Belo Horizonte, v.27, p.105-110, 2006.

SPAYD, S.E.; TARARA, J.M.; MEE, D.L.; FERGUSON, J.C. Separation of sunlight and temperature effects on the composition of Vitis vinifera cv. Merlot berries. American Journal of Enology and Viticulture, Davis, v.53, p.171-182, 2002.

TONIETTO, J.E.; CARBONNEAU, A. Análise mundial do clima das regiões vitícolas e de sua influência sobre a tipicidade dos vinhos: a posição da viticultura brasileira comparada a 100 regiões em 30 países. In: CONGRESSO BRASILEIRO DE VITICULTURA E ENOLOGIA, 9., 1999, Bento Gonçalves. Anais... Bento Gonçalves: Embrapa Uva e Vinho, 1999. p.75-90.

TONIETTO, J.; CARBONNEAU, A. A multicriteria climatic classification system for grape-growing regions worldwide. Agricutural and Forest Meteorology, Amsterdam, v.124, p.81-97, 2004.

TONIETTO, J.; VIANELLO, R.L.; REGINA, M.A. Caracterização macroclimática e potencial enológico de diferentes regiões com vocação vitícola em Minas Gerais. Informe Agropecuário,Belo Horizonte, v. 27, n. 234, p. 32-55, 2006. 